\title{
Synthesis of ABA Triblock Copolymers by a Tandem ROMP-RAFT
}

Strategy

\section{Supporting Information}

Mahesh K. Mahanthappa, Frank S. Bates, and Marc A. Hillmyer

Department of Chemical Engineering and Materials Science and Department of Chemistry, University of Minnesota, Minneapolis, MN 55455 


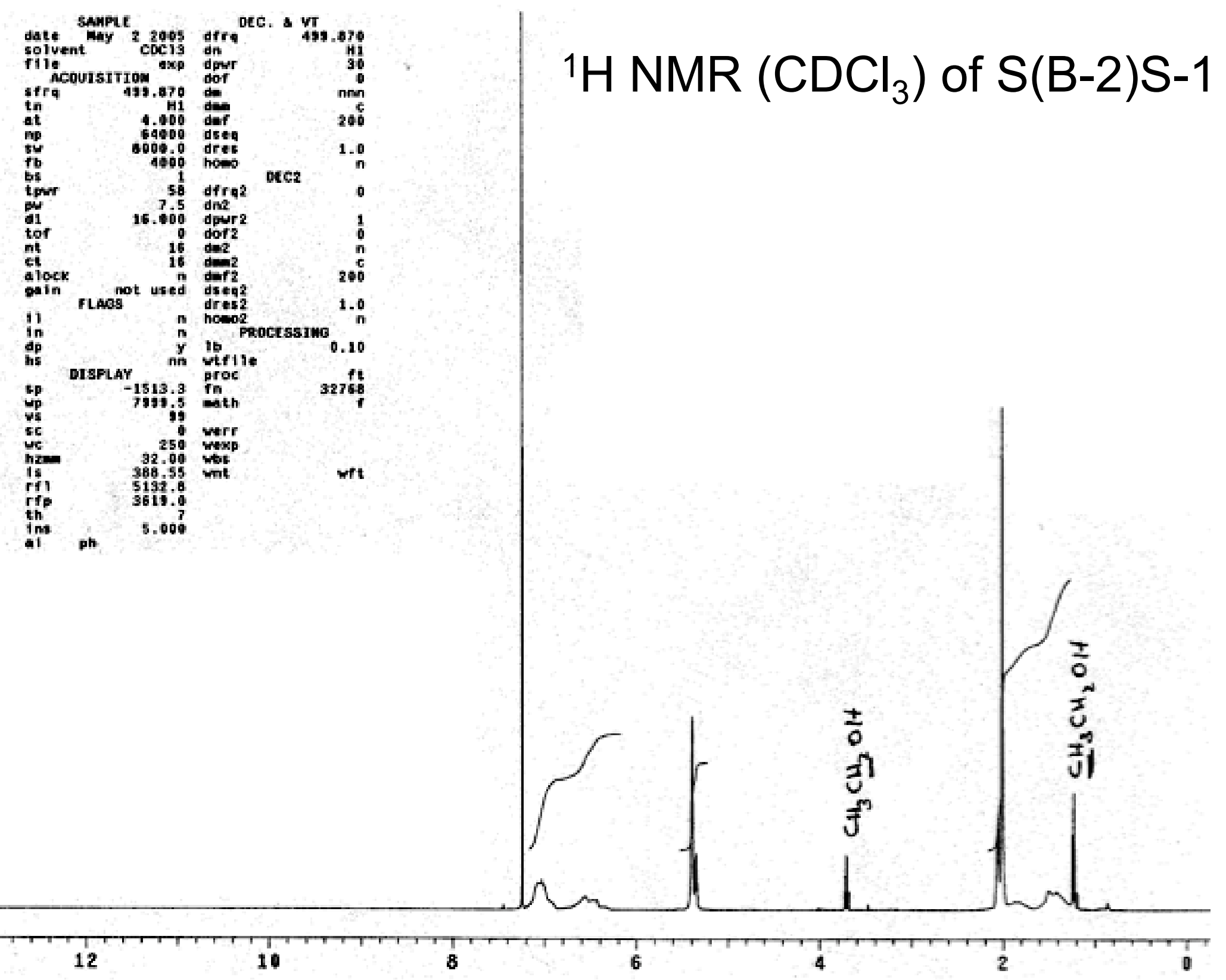




\section{RT-SEC (THF) of S(B-2)S-1}

$\frac{\text { Peak }}{21.09} \underset{24578}{\frac{M n}{37406}} \frac{\mathrm{Mw}}{1.522} \frac{m+\%}{1.000}$

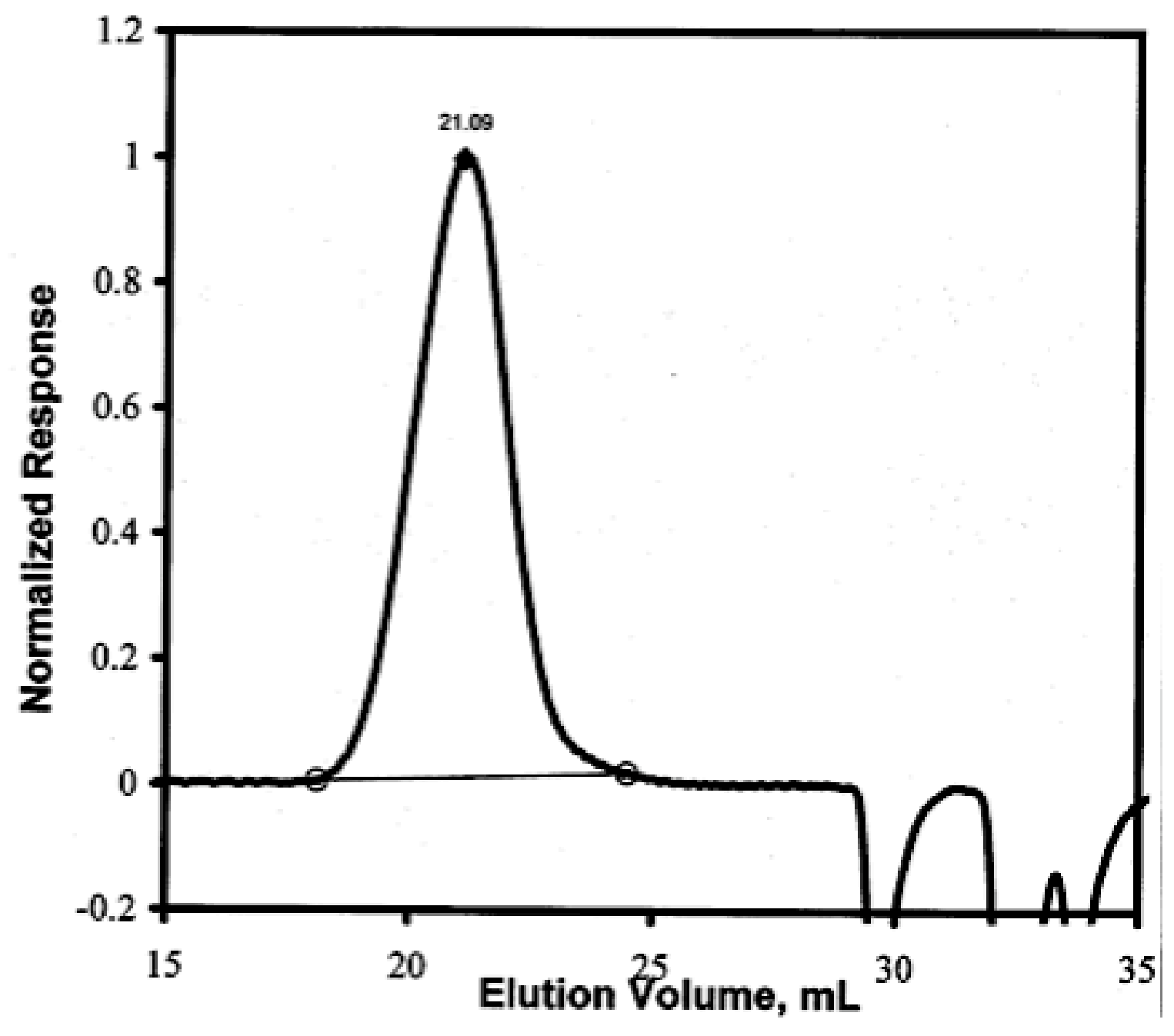




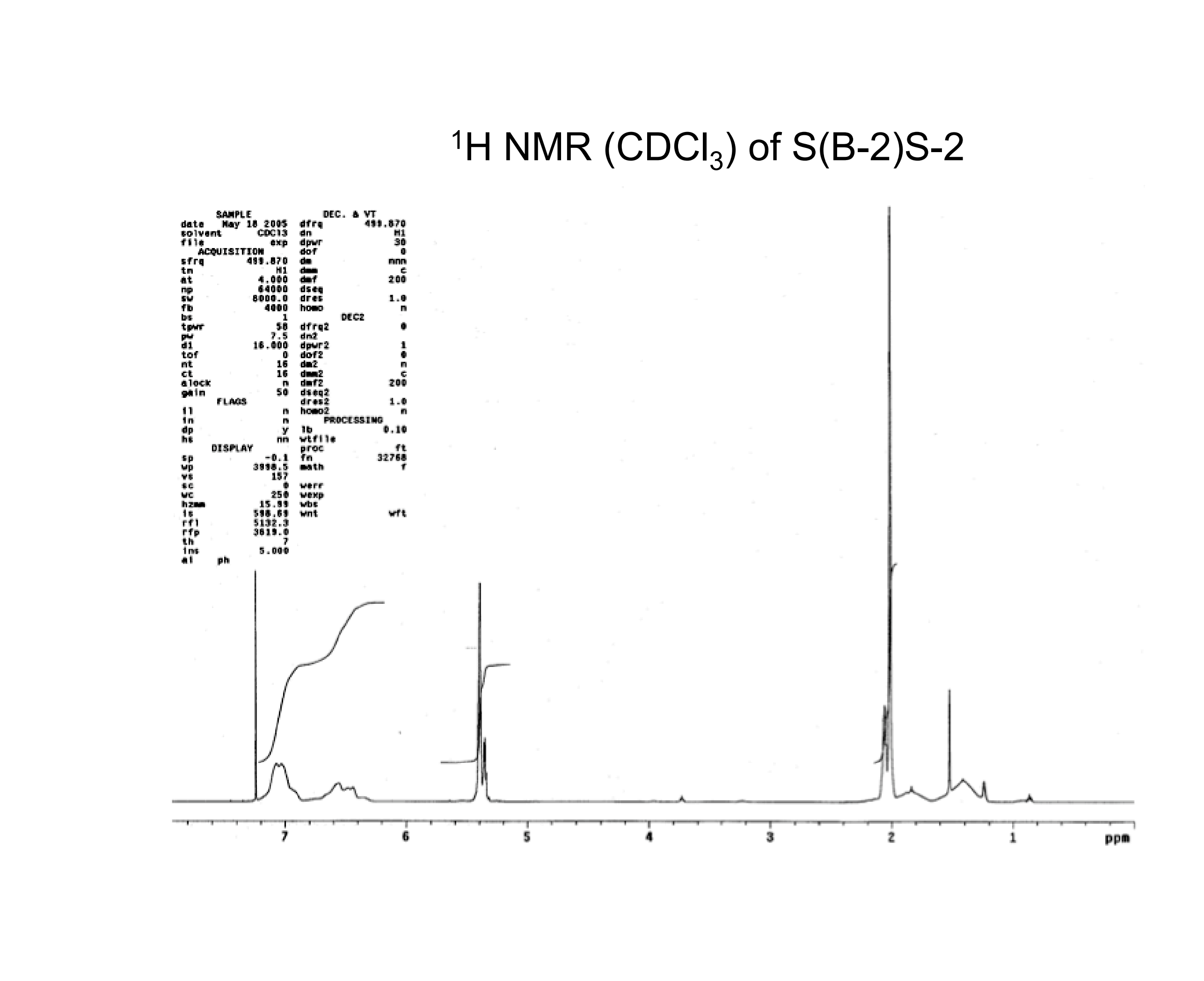




\section{RT-SEC (THF) of S(B-2)S-2}

$\frac{\text { Peak }}{21.09} \quad \frac{\mathrm{Mn}}{25699} \frac{\mathrm{Mw}}{40532} \quad \frac{\mathrm{PDI}}{1.57} \quad \frac{w 1 \%}{1.000}$

MMOS1705

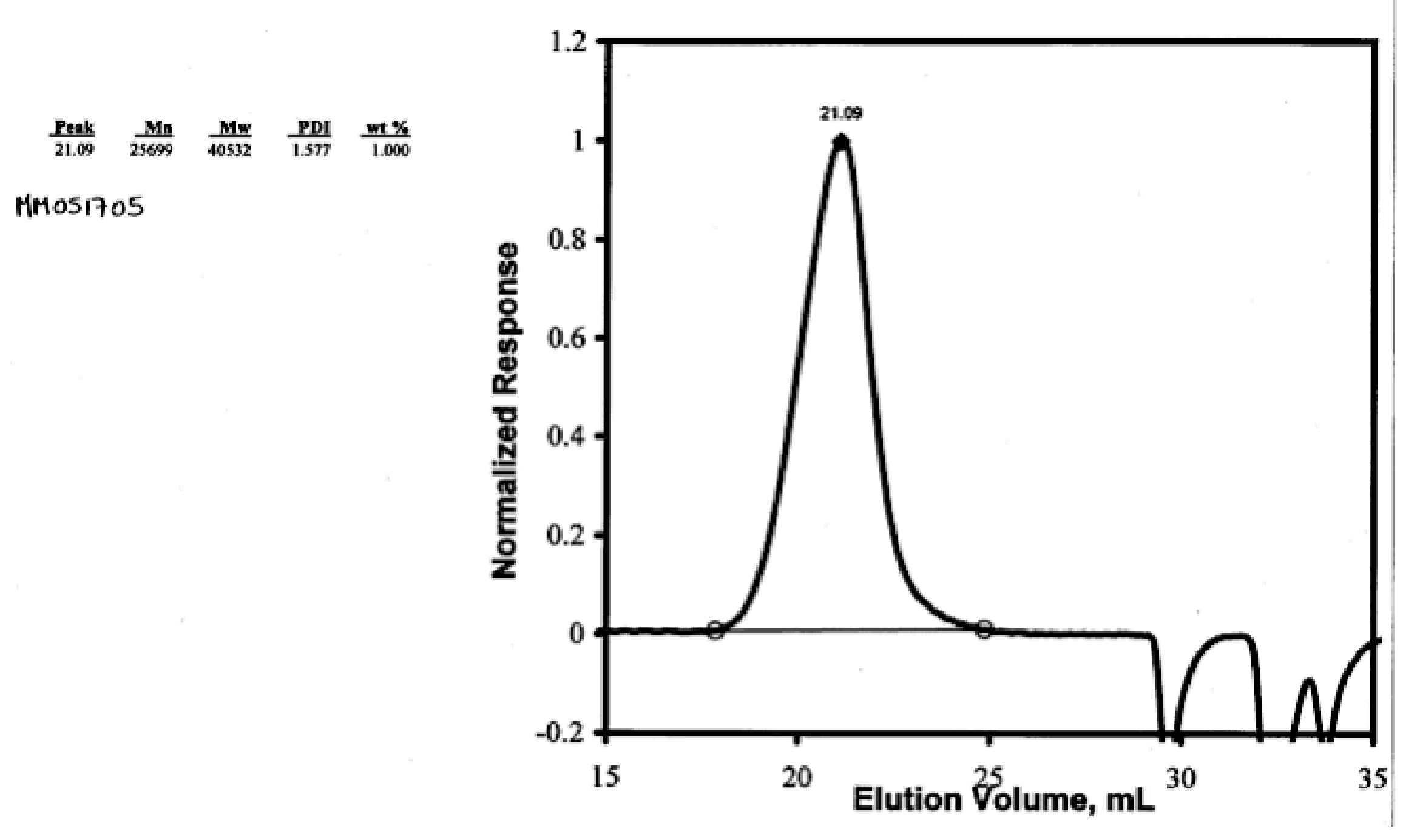




\section{${ }^{1} \mathrm{H}$ NMR $\left(\mathrm{CDCl}_{3}\right)$ of $\mathrm{A}(\mathrm{B}-2) \mathrm{A}-1$}

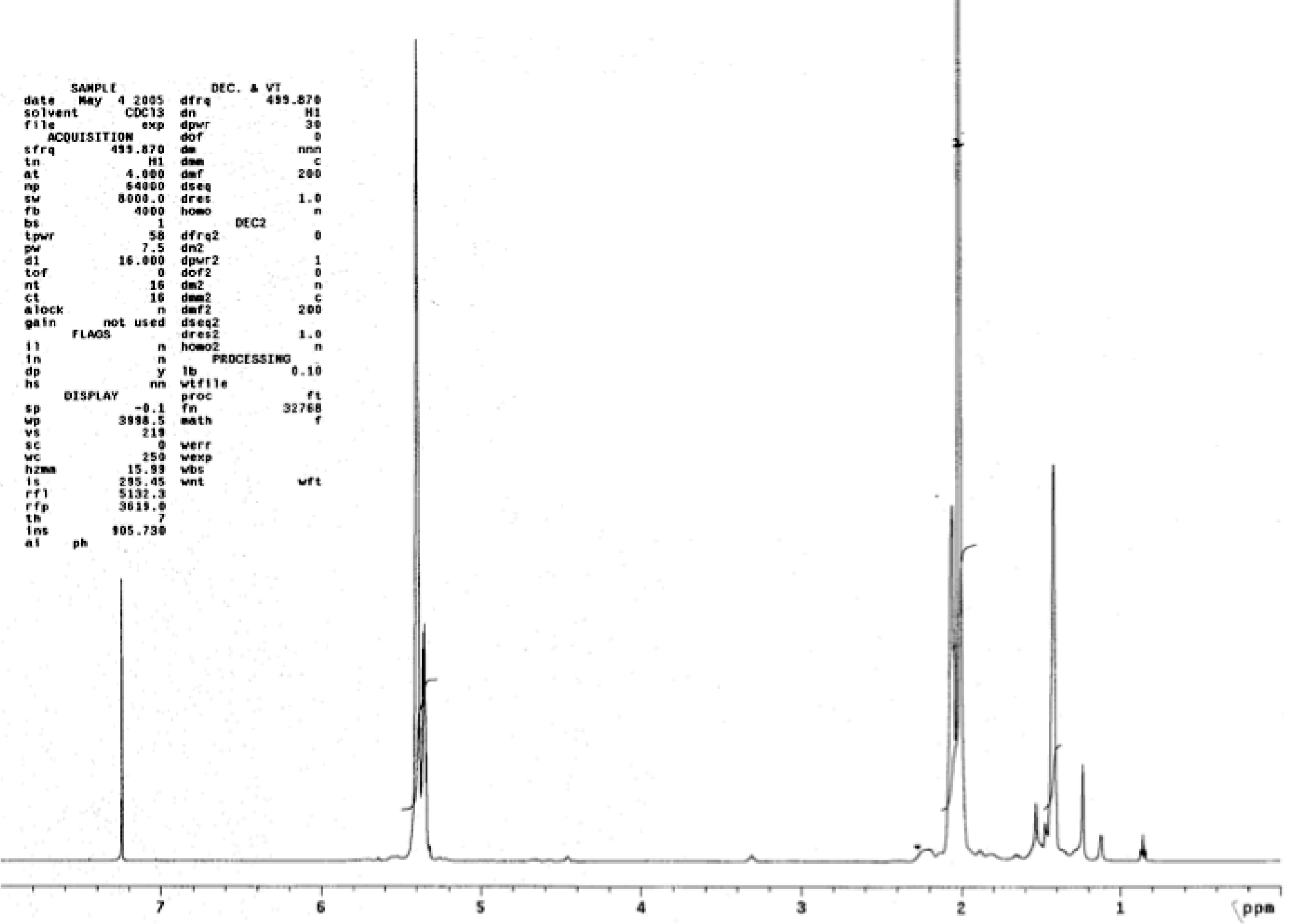




\section{RT-SEC (THF) of $A(B-2) A-1$}

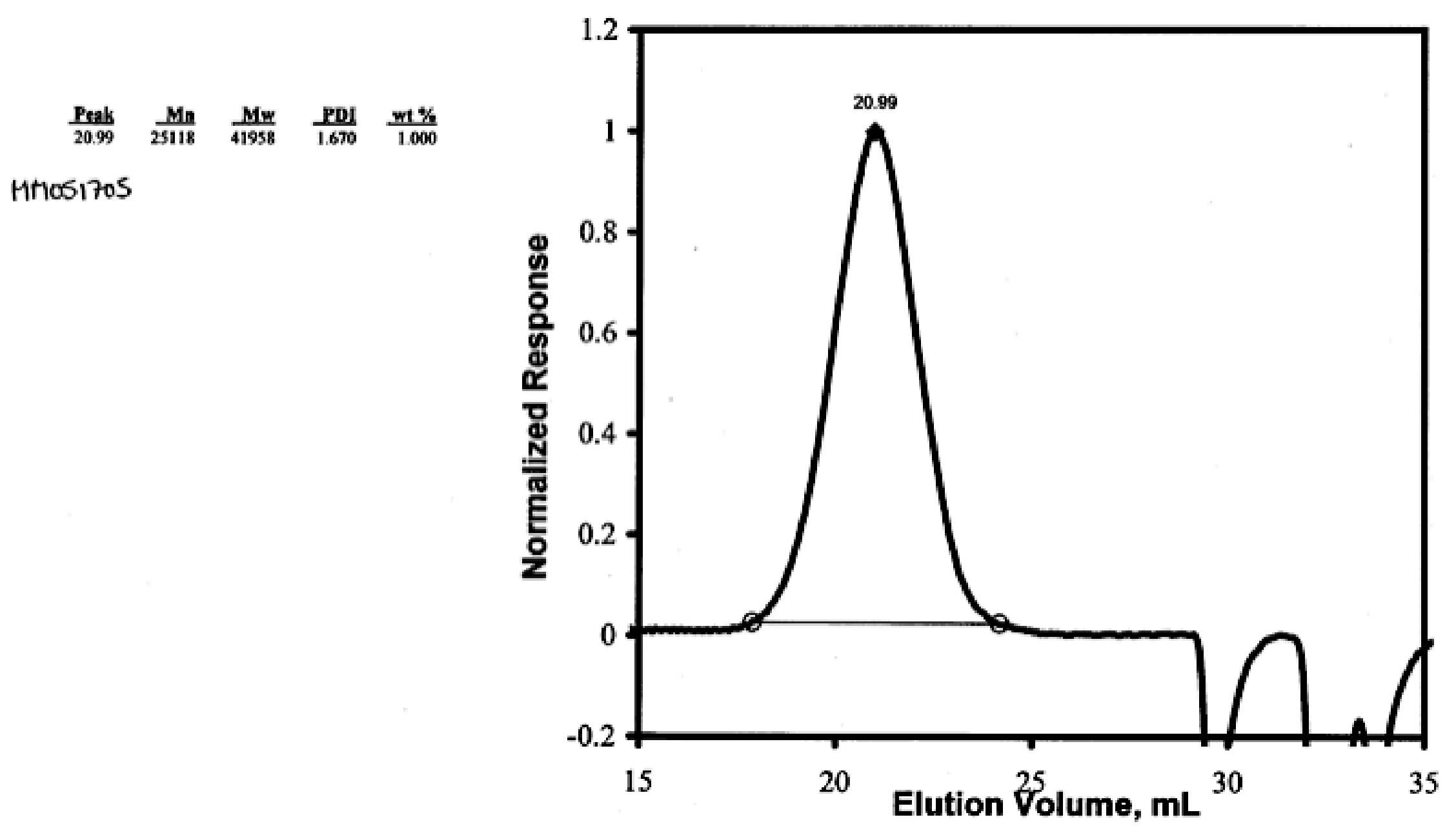




\section{${ }^{1} \mathrm{H}$ NMR $\left(\mathrm{CDCl}_{3}\right)$ of $\mathrm{A}(\mathrm{B}-5) \mathrm{A}-3$}

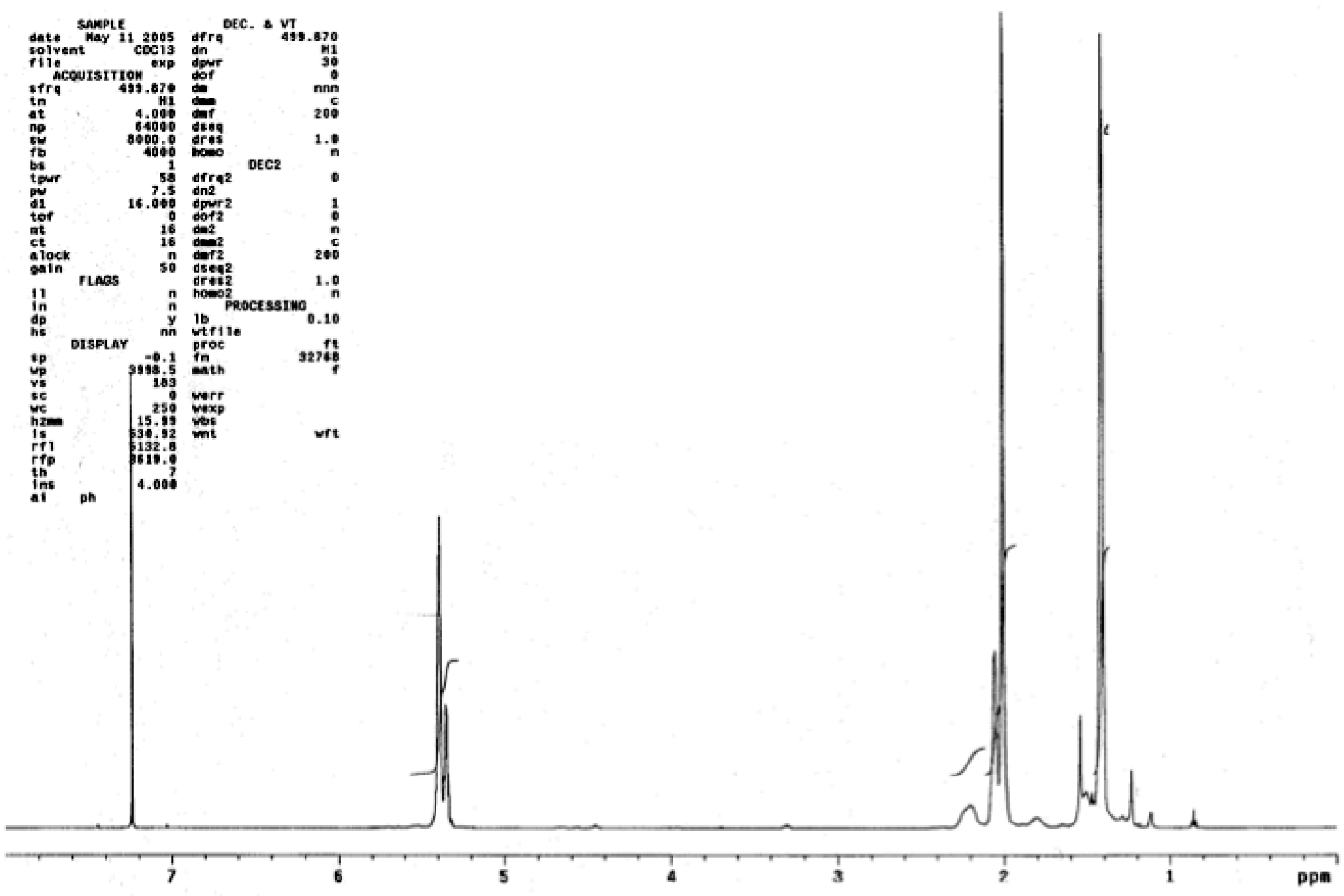




\section{RT-SEC (THF) of A(B-5)A-3}

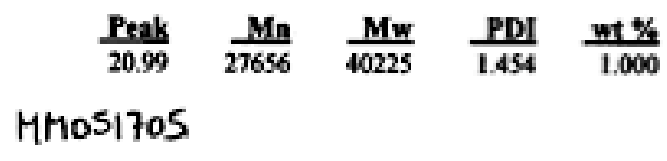

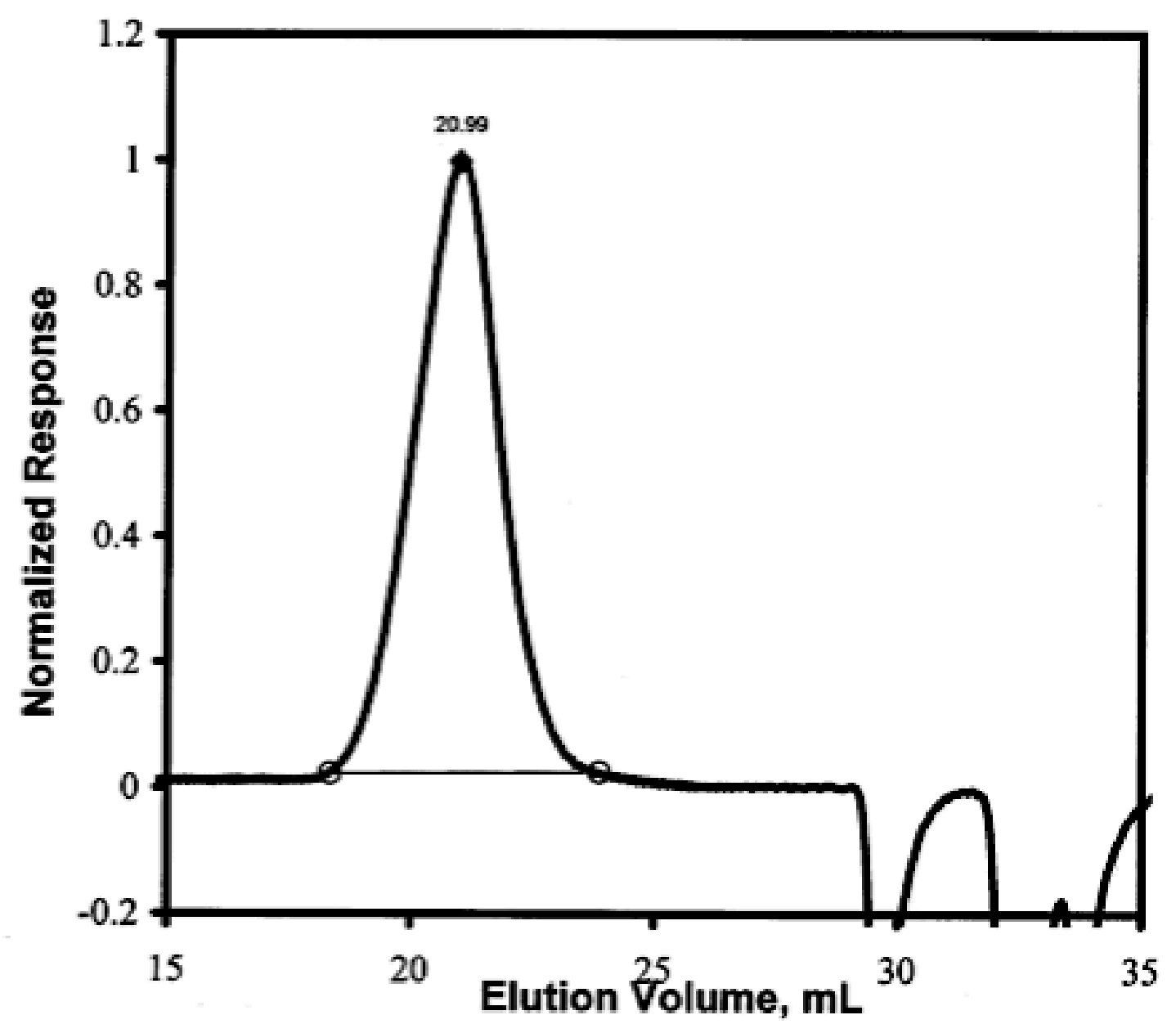

